\title{
Domestic carnivore interactions with wildlife in the Cape Horn Biosphere Reserve, Chile: husbandry and perceptions of impacts from a community perspective
}

\author{
Elke Schüttler Corresp., 1 ， Lorena Saavedra-Aracena ${ }^{1}$, Jaime E Jiménez ${ }^{1,2,3,4}$ \\ ${ }^{1}$ Sub-Antarctic Biocultural Conservation Program, Universidad de Magallanes, Punta Arenas, Región de Magallanes y Antártica Chilena, Chile \\ 2 Department of Biological Sciences, University of North Texas, Denton, Texas, United States \\ 3 Department of Philosophy and Religion, University of North Texas, Denton, Texas, United States \\ 4 Institute of Ecology and Biodiversity (IEB), Santiago, Chile \\ Corresponding Author: Elke Schüttler \\ Email address: elkeschuttler@gmail.com
}

Background. Hundreds of millions of domestic carnivores worldwide have diverse positive affiliations with humans, but can provoke serious socio-ecological impacts when free-roaming. Unconfined dogs (Canis familiaris) and cats (Felis catus) interact with wildlife as predators, competitors, and diseasetransmitters; their access to wildlife depends on husbandry, perceptions, attitudes, and behaviors of pet owners and non-owners.

Methods. To better understand husbandry and perceptions of impacts by unconfined, domestic carnivores, we administered questionnaires $(n=244)$ to pet owners and non-owners living in one of the last wilderness areas of the world, the Cape Horn Biosphere Reserve, located in southern Chile. We used descriptive statistics to provide demographic pet and husbandry information, quantify free-roaming dogs and cats, map their sightings in nature, and report experiences and perceptions of the impact of freeroaming dogs and cats on wildlife. We corroborated our results with an analysis of prey remains in dog feces $(n=53)$. With generalized linear models, we examined which factors (i.e., food provisioning, reproductive state, rural/village households, sex, and size) predicted that owned dogs and cats bring wildlife prey home.

Results. Thirty-one percent of village dogs $(n=121)$ and $60 \%$ of dogs in rural areas $(n=47)$ roamed freely day and/or night. Free-roaming dog packs were frequently observed (64\% of participants) in the wild, including a feral dog population on Navarino Island. Dogs (31 of 168) brought home invasive muskrats (Ondatra zibethicus) and avian prey, and over half of all cats (27 of 51) brought home mainly avian prey. Birds were also the most harassed wildlife category, affected by one third of all dogs and cats.

Nevertheless, dog-wildlife conflicts were hardly recognized ( $<9 \%$ of observed conflicts and suspected problems), and only $34 \%$ of the participants thought that cats might impact birds. Diet analysis revealed that dogs consumed livestock (64\% of 59 prey occurrences), beavers (Castor canadensis, 14\%), and birds (10\%). The probability that dogs brought prey to owners' homes was higher in rural locations and with larger dogs. There was also evidence that cats from rural households and with an inadequate food supply brought more prey home than village cats.

Discussion. Although muskrat, beavers, and birds were brought home, harassed, or found in dog feces, free-roaming dogs and, to a lesser extent, cats are perceived predominantly in an anthropogenic context 
(i.e., as pets) and not as carnivores interacting with wildlife. Therefore, technical and legal measures should be applied to encourage neutering, increase confinement, particularly in rural areas, and stimulate social change via environmental education that draws attention to the possibility and consequences of unconfined pet interaction with wildlife in the southernmost protected forest ecoregion of the globe. 
1 Domestic carnivore interactions with wildlife in the Cape Horn Biosphere Reserve, Chile:

2 husbandry and perceptions of impacts from a community perspective

3

4 Elke Schüttler ${ }^{1}$, Lorena Saavedra-Aracena ${ }^{1}$ and Jaime E. Jiménez ${ }^{1,2,3,4}$

5

$6{ }^{1}$ Sub-Antarctic Biocultural Conservation Program, Universidad de Magallanes, Punta Arenas,

7 Región de Magallanes y Antártica Chilena, Chile

$8{ }^{2}$ Department of Biological Sciences, University of North Texas, Denton, Texas 76201, USA

$9{ }^{3}$ Department of Philosophy and Religion, University of North Texas, Denton, Texas 76201, USA

$10{ }^{4}$ Institute of Ecology and Biodiversity (IEB), Santiago, Chile

11

12 Corresponding Author:

13 Elke Schüttler ${ }^{1}$

14 Teniente Muñoz 396, Puerto Williams, Región de Magallanes y Antártica Chilena, Chile

15 Email address: elkeschuttler@gmail.com 


\section{Abstract}

Background. Hundreds of millions of domestic carnivores worldwide have diverse positive affiliations with humans, but can provoke serious socio-ecological impacts when free-roaming. Unconfined dogs (Canis familiaris) and cats (Felis catus) interact with wildlife as predators, competitors, and disease-transmitters; their access to wildlife depends on husbandry, perceptions, attitudes, and behaviors of pet owners and non-owners.

Methods. To better understand husbandry and perceptions of impacts by unconfined, domestic carnivores, we administered questionnaires $(n=244)$ to pet owners and non-owners living in one of the last wilderness areas of the world, the Cape Horn Biosphere Reserve, located in southern Chile. We used descriptive statistics to provide demographic pet and husbandry information, quantify free-roaming dogs and cats, map their sightings in nature, and report experiences and perceptions of the impact of free-roaming dogs and cats on wildlife. We corroborated our results with an analysis of prey remains in $\operatorname{dog}$ feces $(n=53)$. With generalized linear models, we examined which factors (i.e., food provisioning, reproductive state, rural/village households, sex, and size) predicted that owned dogs and cats bring wildlife prey home.

Results. Thirty-one percent of village $\operatorname{dogs}(\mathrm{n}=121)$ and $60 \%$ of dogs in rural areas $(\mathrm{n}=47)$ roamed freely day and/or night. Free-roaming dog packs were frequently observed (64\% of participants) in the wild, including a feral dog population on Navarino Island. Dogs (31 of 168) brought home invasive muskrats (Ondatra zibethicus) and avian prey, and over half of all cats (27 of 51) brought home mainly avian prey. Birds were also the most harassed wildlife category, affected by one third of all dogs and cats. Nevertheless, dog-wildlife conflicts were hardly recognized $(<9 \%$ of observed conflicts and suspected problems), and only $34 \%$ of the participants thought that cats might impact birds. Diet analysis revealed that dogs consumed livestock (64\% of 59 prey occurrences), beavers (Castor canadensis, 14\%), and birds (10\%). The probability that dogs brought prey to owners' homes was higher in rural locations and with larger dogs. There was also evidence that cats from rural households and with an inadequate food supply brought more prey home than village cats.

Discussion. Although muskrat, beavers, and birds were brought home, harassed, or found in dog feces, free-roaming dogs and, to a lesser extent, cats are perceived predominantly in an anthropogenic context (i.e., as pets) and not as carnivores interacting with wildlife. Therefore, technical and legal measures should be applied to encourage neutering, increase confinement, particularly in rural areas, and stimulate social change via environmental education that draws 
50

51

52

53

54

55

56

57

58

59

60

61

62

63

64

65

66

67

68

69

70

71

72

73

74

75

76

77

attention to the possibility and consequences of unconfined pet interaction with wildlife in the southernmost protected forest ecoregion of the globe.

\section{Introduction}

In parallel with human population growth, the number of companion animals is constantly increasing. Pet and feral dogs (Canis familiaris) have reached an estimated population of 900 million while cat (Felis catus) populations are estimated at 600 million (O'Brien \& Johnson, 2007; Gompper, 2014a), existing on all continents except Antarctica (Hughes et al., 2015). Since their domestication thousands of years ago, domestic dogs have had profound roles in human lives. These include companionship, livestock guarding, rescue, hunting, tourism, service animals, and wildlife management (Hart \& Yamamoto, 2017). As dogs are part of a diversity of human cultures, their various roles, husbandry, and people's attitudes towards them have different implications for human-dog-wildlife interactions (Miller, Ritchie \& Weston, 2014).

The potential for interactions with wildlife depends on dogs' and cats' husbandry, particularly on their confinement. This ranges from complete mobility restriction, for leashed and/or indoor dogs and cats, to feral domestic carnivores that survive independently of supplemental provisioning from humans (Kays \& DeWan, 2004; Vanak \& Gompper, 2009). Between these extremes, there exists a range of free-roaming animals that are owned or unowned and are, to some extent, subsidized by humans. As subsidized predators, domestic carnivores can reach higher population densities than wild carnivore populations (Gompper, 2014b), leading to complex socio-ecological consequences.

The impacts of free-roaming subsidized and feral domestic dogs include loss of livestock (Baker et al., 2008; Echegaray \& Vilà, 2010), aggression towards humans (Schalamon et al., 2006), disease transmission (Matter \& Daniels, 2010), and wildlife interference (reviewed in Young et al., 2011; Hughes \& Macdonald, 2013; Doherty et al., 2017). Dogs prey upon (Butler, du Toit \& Bingham, 2004; Manor \& Saltz, 2004), compete with (Mitchell \& Banks, 2005; Vanak, Thaker \& Gompper, 2009), infect (Acosta-Jamett, 2009), and disturb (Silva-Rodríguez, Ortega-Solís \& Jiménez, 2010; Silva-Rodríguez \& Sieving, 2012) wild animals. Suburban cats are successful small vertebrate predators (Woods, McDonald \& Harris, 2003; Loyd et al., 2013). On islands, Medina et al. (2011) demonstrated that feral cats were responsible for at least $14 \%$ of global avian, 
80

81

82

mammalian, and reptilian extinctions (see also Nogales et al., 2013). Finally, both dogs and cats may hybridize with their wild relatives (Randi, 2008).

While the biology of domestic carnivore-wildlife interactions is often the focus of research, studies on social dimensions are still in their infancy (Miller, Ritchie \& Weston, 2014). Understanding the perceptions of free-roaming pet carnivores is indispensable to inform conservation action, because the causes and solutions to this problem directly depend upon the nature of relationships between humans and their domestic pets (Gramza et al., 2016). Conflicts between dogs/cats and wildlife could thus be minimized by a better understanding of how husbandry, attitudes, and behaviors of pet owners influence dogs and cats in their access to and interaction with wild prey or carnivores, particularly when close to protected areas. For example, dog owners felt more obliged to leash their dogs when they thought their dog would harm beachnesting birds or people (Williams et al., 2009). Recent studies have shown that a more adequate diet (i.e., commercial or prepared food instead of e.g., household scraps) for dogs and cats decreases the probability of preying upon wild animals (Silva-Rodríguez \& Sieving 2012, Sepúlveda et al., 2014). Additionally, in the absence of biological data or for logistical and cost reasons, a community-based assessment may provide suitable information on the impact of particular species on other species (White et al., 2005).

Here, we focus on understanding the interactions with wildlife by populations of freeroaming dogs and cats in a sensitive conservation area of southern Chile, the Cape Horn Biosphere Reserve, from a community perspective. To date, the only substantial human impacts in the biosphere reserve are biological invasions, particularly of wild and domestic exotic mammals that outnumber their native counterparts (Anderson et al., 2006). Additionally, native terrestrial predators are absent on many of the islands of the reserve, including Navarino Island, where the only village of the reserve is located (Anderson et al., 2006). Thus, introduced predators may cause extensive population reductions on native and often naïve prey (discussed in Sih et al., 2010). Although free-roaming and feral dogs are commonly observed by locals on Navarino Island, there are few observations of their impacts. Dogs have been reported to prey upon the southernmost population of guanacos (Lama guanicoe), which is virtually unstudied and considered in danger of local extinction (Cunazza, 1991; Gónzalez, 2005). Evidence also exists of dogs preying upon nests of solitary nesting waterfowl, such as the Flightless Steamer Duck (Tachyeres pteneres), a 
110 species endemic to Patagonia, and nesting colonies of the South American Tern (Sterna

111

112

113

114

115

116

117

118

119

120

121

122

123

124

125

126

127

128

129

130

131

132

133

134

135

136

137

138

139

140

hirundinacea, Schüttler et al., 2009). There are no published accounts of local cat impacts.

We administered questionnaires to pet owners and non-owners to address the following objectives: (1) provide demographic and husbandry information relevant for future dog and cat management in one of the last wilderness areas of the globe, (2) quantify free-roaming dogs and cats and map their locations in nature, (3) examine experiences and perceptions of the impact of free-roaming dogs and cats on wildlife and corroborate those with an analysis of prey remains of dog feces, and (4) predict which factors best explain when owned dogs and cats bring wildlife prey home. With regard to the paucity of ecological data on domestic carnivore-wildlife interactions in this sub-Antarctic wilderness area, this study allows a first insight into this conservation problem.

\section{Materials \& Methods}

\section{Ethics statement}

We obtained prior informed consent from each participant by reading a printed statement explaining the project aims, the lack of risks in participating, the possibility of omitting questions, information about use of and access to the results, and that the interview was anonymous and voluntary. The participants agreed to participate by signing a copy of the informed consent; they were also given a copy. Paper and digital questionnaires were stored anonymously. The Scientific Ethical Committee of the University of Magallanes, Chile, certified ethical approval of the instrument.

\section{Study area}

We carried out this study in the Cape Horn Biosphere Reserve (CHBR) $\left(19,172 \mathrm{~km}^{2}\right.$ terrestrial surface), Chile, located at the extreme southern tip of South America (Fig. 1). The biosphere reserve exists within the Magellanic Sub-Antarctic forest ecoregion, one of the remaining 24 wilderness areas of the world (Mittermeier et al., 2003). The dominant habitats within this ecoregion are unfragmented evergreen and deciduous southern beech (Nothofagus spp.) and Winter's bark (Drimys winteri) forests, Magellanic peat bogs (predominantly Sphagnum spp.), high-Andean habitats, and glaciers (Pisano, 1977). The human population in the CHBR is of mixed cultural and ethnic origin (i.e., Yaghan indigenous people, Chilean Navy, fishermen, and Chilean 
141 and foreign short- and long-term settlers) and is concentrated in the only town within the reserve,

142 Puerto Williams (2,800 inhabitants) on Navarino Island. A small fishing village, Puerto Toro, 143 exists on the eastern coast of Navarino as well as eight rural farm settlements. In the remainder of 144 the biosphere reserve, there are only 11 Chilean Navy posts operated by a new family each year, 145 and one farm on Hoste Island (Fig. 1). The principal economic activities on Navarino Island 146 include fishing, tourism, and small-scale livestock farming. The infrastructure is limited to a dirt 147 road along the northern coast of Navarino; public maritime transport within the reserve does not 148 exist.

[please insert Figure 1 here]

151

152

153

154

155

156

157

158

159

160

161

162

163

164

165

166

167

168

169

170

171

\section{Survey}

From May 2015 to April 2016, we interviewed 215 households in Puerto Williams, seven farm owners on Navarino Island, and 22 Chilean Navy families living for one year on the 11 Navy posts on different islands in the CHBR ( $n=244$ total interviews). To test the questionnaire design and adapt the questions, we conducted a pilot study with four trial informants who were later excluded from the dataset.

We calculated a representative $95 \%$ probability sample of 215 interviewees in Puerto Williams based on a census of households conducted by ES in May 2015 (490 houses). We used a confidence interval of 5\% and applied the finite population correction for smaller populations (Bernard, 2006: 183). We randomly chose 280 households from a map of numbered houses in town (adding 30\% to the sample size of 215 to correct for non-responses). When an adult was not present, we left a written message explaining the motivation for our visit and our contact information. We visited each household up to three times before it was replaced. The questionnaires were administered at different times in a face-to-face interview at the participant's home and took 10-30 min. Two interviewers conducted the interviews in Spanish ( $\mathrm{n}=92$ by ES and $\mathrm{n}=152$ by LSA).

To meet objective 1, we collected information on dog and cat demographics (i.e., number, age, sex, origin, purpose of pets, number of pups/kittens in previous year, elimination, and temporary and definite pet loss) as well as on pet care/husbandry (i.e., veterinary treatments, food type, in how many households pets eat, and whether owned or unowned street dogs are fed). We 
172 asked participants whether they restricted the movements of their dogs (i.e., day and/or night and

173 if free-ranging, why), whether they saw unaccompanied dogs and cats (adults, pups/kittens)

174 outside of town and from where they thought the animals came (objective 2). We asked participants

175 about their observations of problematic dog situations in and out of town, perceptions of possible

176 impacts of free-roaming dogs and cats, and their personal experiences regarding the pet's

177 interaction(s) with other animals (objective 3). To better understand predictors (i.e., food

178 provisioning, reproductive state, rural/village households, sex, size) of dog and cat interactions

179 with wildlife, we asked owners whether their pets brought wildlife prey home (objective 4). We

180 finished the questionnaire by asking for suggestions for reducing the number of free-roaming dogs,

181 personal data (i.e., age, sex, education, residence time), and the owner's permission to take a photo

182 of their pet. From this photo, we then classified dog sizes (i.e., small, medium, large) and calculated

183 the mean of two independent estimations by ES and LSA. For farm owners, we added questions

184 on their experience with the loss of domestic animals such as cattle (Bos taurus) or sheep (Ovis

185 aries) to dog attacks. For participants without pets, non-relevant questions were not asked. Some

186 questions were focused only on dogs because dogs produce visible socio-ecological conflicts in

187 the study area.

\section{Dog diet}

Dog feces of owned and feral dogs $(\mathrm{n}=70)$ were opportunistically collected within one $\mathrm{km}$ of the 11 Navy posts and during trekking events on Navarino Island (June 2015 to April 2016).

192

193

194

195

196

197

198

199

200

201

202 Each sample was dried, rehydrated, and degreased with detergent, and then grouped into hair,

bones, feathers, and rubbish. Using a microscope, we examined the medullary and cuticular patterns of guard hairs to identify up to species level using gelatin as the printing medium (similar to González-Esteban, Villate \& Irizar,1996). As reference collections, we used those provided by the Instituto de la Patagonia, Universidad de Magallanes, complemented by our own additions, and local keys (Chehébar \& Martín, 1989). Unfortunately, we could not find a major number of cat feces from different individuals for a sound analysis of cat diet.

\section{Statistics}

We first calculated descriptive statistics to analyze basic demographic and husbandry information from the interviews to quantify (i) the number of free-roaming dogs and cats, (ii) 
203 problems associated with dogs, (iii) perceptions of the potential impact of free-roaming dogs and 204 cats on wildlife, (iv) occurrence of predation and harassment by dogs and cats, and (v) percentages 205 of different types of prey in dog feces. We then used generalized linear models (GLMs) to examine 206 predictors of interactions with wildlife of owned dogs and cats (Table 1). Our response variable 207 for the dog and the cat model was whether pets brought wildlife home, defined here as any exotic 208 or native wild mammal or bird (PREY). As covariates, we considered diet (dinner leftovers and/or 209 commercial pet food) provided by the animal's owner (FOOD), sex (SEX), sterility 210 (STERILIZED), owners' household location (LOCATION, rural or village), and pet size (SIZE, 211 only for dogs). We focused on those covariates as they might identify pet characteristics or levels 212 of care which can then inform recommendations for pet management for the benefit of wildlife.

213 The location was included because rural households are imbedded in wilderness settings and 214 access to wildlife is immediate. Response and predictor variables are explained in detail in Table 2152.

As the response variable of the two models was binomial, we fitted generalized linear models (GLMs) with binomial error structure and logit link. The models were parameterized with all possible covariate combinations. Prior to analysis, we explored these data following Zuur et al. (2010). Collinearity between ordinal covariates was assessed with Spearman correlation coefficients (no coefficients were $>|0.4|$ ). We tested the independence of categorical variables using contingency tables (Chi-square and Fisher's exact tests, $\mathrm{p}<0.05$ ). We removed SEX and STERILIZED from the dog model for being significantly associated with LOCATION; similarly, we removed STERILIZED from the cat model for being significantly associated with LOCATION and SEX. FOOD was maintained here, despite its collinearity with LOCATION, to test the same variables in the dog and cat models (the conclusions for models tested with and without FOOD were identical, see Mundry, 2014, for treating collinearity). For model selection, we used Akaike's Information Criterion corrected for small sample size $\left(\mathrm{AIC}_{\mathrm{c}}\right)$. We tested for an interviewer effect by including interviewer as a random effect in the models (generalized linear mixed models, GLMMs), but did not detect any (AIC GLMMs >AIC GLMs of the global models, respectively). We accounted for model selection uncertainty (model weights $\omega_{i}$ were $<0.9$ ) using full-model averaging (Symonds \& Moussalli, 2011). To rank predictor variables in terms of importance, we summed Akaike weights for each model in which the variable under consideration appeared (Burnham \& Anderson, 2002). We explored the direction of predictor impacts on the response 
234 variable by calculating log odds ratios of the averaged estimates with $95 \%$ confidence intervals.

235 Statistical modelling was conducted in R (R Core Team, 2016).

236

237 [Please insert Table 1 here]

238 [Please insert Table 2 here]

239

240

Results

241

242

We conducted 215 interviews in Puerto Williams, seven in rural households, and 22 with

Navy post families. Only five people in Puerto Williams refused to participate. Of the 244 participants, 61.5\% were female, mean participant's age was 39.5 years (SD 11.6, range 18-76 years), and mean residence time in the biosphere reserve was 11.6 years (SD 14.2, range one month-66 years).

The Puerto Williams participants owned 121 dogs and 36 cats, predominantly for companionship. The seven farm households owned 30 dogs and 15 cats, mainly kept as working dogs and for rodent control, respectively. The 22 Navy families owned 17 dogs primarily for companionship and two cats for rodent control. Two dogs and two cats stayed at the Navy post when families were exchanged after one year ("inherited animals"), the others left with their families. Reproductive control was moderate to high in Puerto Williams (41.7\% of dogs and 19.4\% of cats not sterilized), but almost absent in rural areas (83.3\% dogs, 93.3\% cats) and Navy posts (86.7\% dogs, $100 \%$ cats, but 9 of 17 dogs were $\leq 1$-year, Table 3 ). Additionally, four participants had eliminated unwanted dog pups.

In Puerto Williams, over half of the dogs and around one third of the cats were vaccinated against rabies (55.4\% and 33.3\%, respectively) and treated for parasites $(60.3 \%$ and $36.1 \%$, respectively). Pet owners in rural households did not vaccinate against rabies, but treated for parasites (100\% dogs, $40.0 \%$ cats). At Navy posts, only dogs were vaccinated and dewormed (64.7\%). Pets in Puerto Williams, rural dogs, and dogs at Navy posts were provided mainly with commercial food and/or meat (>77.7\%). However, 35 village dogs $(28.9 \%)$ were fed in more than one household, and 74 interviewees in town (34.4\%) reported feeding street dogs on a regular basis (71.8\% at least once a week), mostly with leftovers (73.5\% of 83 mentioned food items).

Sixty-five of 168 dogs (38.7\%) roamed freely day or night and 39 dogs $(23.2 \%)$ were 
265 Williams ( $\mathrm{n}=275.8$ with $1.4 \mathrm{dogs} /$ household), we estimate that 84 dogs $(30.6 \%)$ roam freely in 266 town during day or night. The most common method of dog restriction $(69.4 \%$ in town, 53.3\% 267 rural, 17.6\% Navy posts) was keeping dogs in the house (63.6\% of 121 responses), fewer were 268 kept free in the yard $(18.2 \%)$ or leashed $(18.2 \%)$. Reasons mentioned for allowing unrestricted 269 movement of dogs in town and rural environments were (i) the owner claimed animal freedom, 270 (ii) leashing may increase aggressiveness, (iii) acclimation to free-roaming and releasing energy, 271 (iv) the dog is not dangerous, and (v) unsuitable facilities (together $77.2 \%$ of 70 explanations). 272 Also, 44.0\% of 91 non-pet owners thought that street dogs enjoyed their freedom, and most dog 273 owners $(87.2 \%$ of 86$)$ thought that street dogs roamed into the forest. Finally, 22 of 168 dogs 274 (13.1\%) went missing between 12-24 hours during the last year (2014/15), among which 13 dogs 275 had disappeared up to one week before returning home. Cats disappeared more frequently $(\mathrm{n}=18$, $27634.0 \%$ ); 14 cats for 2-7 days. Over the last 10 years, 35 pets (23 dogs, 12 cats) never returned.

277

278 [Please insert Table 3 here]

279

280

281

282

283

284

285

286

287

288

289

290

291

292

293 294 1-25, Fig. 2) in this area.

\section{[Please insert Figure 2 here]}

Free-roaming dogs not accompanied by people outside of town were frequently observed on Navarino Island (63.9\% of 244 participants), whereas cat sightings in the wild were almost absent (6.1\%, Fig. 2). The greatest distance of sighted dogs and cats was $19.4 \mathrm{~km}$ and $5.2 \mathrm{~km}$ from the northern settled coast, respectively. Neither dogs nor cats were seen roaming around Navy posts, except near the two posts on Navarino Island. Dogs were mostly observed in packs, with a median pack size of four dogs (mean 6.6, SD 7.5, range 2-60, $\mathrm{n}=172$ sightings), while only $9.2 \%$ of the sightings were single dogs. Dog pups (abandoned or feral) outside Puerto Williams were sighted by 52 participants (21.3\%) with a mean litter size of 4.0 (SD 2.3, range 1-12). Four participants observed pups and kittens $(n=17)$ abandoned in cardboard boxes outside town. Apparently, the landfill, approximately $500 \mathrm{~m}$ from Puerto Williams, was a point of attraction for dogs, as 12 participants observed dog packs with a median size of eight (mean 10.75, SD 8.0, range 
Over half of the participants $(55.9 \%, \mathrm{n}=222)$ on Navarino Island had experienced problems

296

297

298

299

300

301

302

303

304

305

306

307

308

309

310

311

312

313

314

315

316

317

318

319

320

321

322

323

324

325

with dogs in Puerto Williams during 2009-2015 (83.9\% had occurred during the last year, 2014/15), whereas 41 participants (18.5\%) reported problems outside the town $(61.4 \%$ during 2014/2015). Predominant dog problems in town were conflicts with people (biting, attacking, frightening, disease transmitting, accidents, and stealing; $40.6 \%$ of 143 problems, $24.1 \%$ concerned children) and free-ranging domestic animals (cows, horses, and their offspring) in town, mostly foals (37.1\%, Fig. 3). Outside of town, people experienced conflicts between dogs and domestic animals, particularly involving cattle (77.3\% of 44 problems), whereas only two people saw dogs feeding on wildfowl eggs (4.5\%).

Beyond personal experiences, most participants thought that free-roaming dogs caused problems both in and outside of town (91.9\% and $89.2 \%$, respectively). In town, suspected dog problems mainly involved people (68.8\% of 221 problems), whereas outside of town concerns involved domestic animals as well as people (Fig. 3). Dog-wildlife conflicts (e.g., involving guanacos) were only mentioned 19 times (9.4\% of 202 problems). However, when asked directly whether feral dogs could have negative impacts on wildlife and what kind of wildlife could be affected, most participants said yes $(80.8 \%, \mathrm{n}=239)$ regarding birds $(67.3 \%$ of 349 problems). Guanacos were only mentioned 16 times among the affected wildlife (4.6\%).

Regarding suspected cat problems, only one third of participants (33.8\% of 240$)$ associated problems with them outside of town, particularly with cats harassing and eating wild birds and their eggs (67.5\% of 77 problems, Fig. 3$)$.

Five of seven farm owners reported losing domestic animals due to unrestricted dogs from Puerto Williams or feral dogs during 2014/15. The estimated total loss during these events were 62 calves, 25 cows, and 30 sheep, while 30 sheep and 2 calves were injured. The losses on the five farms corresponded to $3.3 \%, 11.5 \%, 16.7 \%, 18.8 \%$, and $35.0 \%$ (cows), and $75.0 \%$ (sheep) of owned livestock.

[Please insert Figure 3 here]

Thirty-one village and rural dogs (18.5\%) brought prey home, mainly invasive muskrats $(32.5 \%)$ and birds (27.5\%, Fig. 4). Among avian prey were songbirds (Austral Blackbird Curaeus curaeus, Austral Thrush Turdus falcklandii, Rufous-collared Sparrow Zonotrichia capensis), 
326

327

328

329

330

331

332

333

334

335

336

337

338

339

340

341

342

343

344

345

346

347

348

349

350

351

352

353

354

355

356

waterbirds (terns, Upland Goose Chloephaga picta), and raptors (Chimango Caracara Milvago chimango). Over one third of all dogs $(n=64)$ were observed harassing (but not killing) other animals, particularly birds (38.0\% of 79 items mentioned: Chimango Caracara, Patagonian SierraFinch Phrygilus patagonicus, Upland Goose, and ducks such as Flightless Steamer Ducks), other dogs (16.5\%), and horses (15.2\%); three dogs harassed native mammals (i.e., foxes and seals).

Over half of all village and rural cats $(n=27)$ brought prey home (birds were $57.6 \%$ of 33 prey items): among songbirds, the Austral Thrush, Fired-eyed Diucon Xolmis pyrope, House Sparrow Passer domesticus, Patagonian Sierra-Finch, and among waterbirds, ducks and terns. Birds were also the most commonly harassed prey group (72.0\%) by 18 cats (only one species referred to here: Patagonian Sierra-Finch). The 244 participants mentioned diverse food items they thought feral dogs would eat (Fig. 4). Domestic livestock was the most important group mentioned (39.9\%), whereas native birds and guanacos were less recognized (15.2\% and $2.2 \%$, respectively).

[Please insert Figure 4 here]

Of 70 fecal samples from owned and feral dogs in rural zones of the CHBR, we could not identify prey remains in seven, and 10 feces were excluded for only containing dog hair. The subsequent diet analysis revealed that the main food item (64.4\% of 59 prey occurrences) found in 53 feces was ungulates (i.e., horses and cows, which could not be distinguished here), followed by beavers $(13.6 \%)$, birds $(10.2 \%)$, mice $(5.1 \%)$, rubbish $(5.1 \%)$, and Fuegian red fox (Pseudalopex culpaeus, 1.7\%).

Three models best explained whether dogs would bring prey home (Table 4). The most important variable with the highest summed Akaike weights ( $\omega$, upper limit=1.0) was LOCATION $(\omega=0.99)$; FOOD $(\omega=0.54)$ and SEX $(\omega=0.30)$ had less importance. The averaged estimates indicated that dogs in rural areas were more likely to bring prey home (Fig. 5A), whereas an adequate diet and the dog's sex had little influence (their confidence intervals overlapped the odds ratio at one). LOCATION $(\omega=0.99)$ and FOOD $(\omega=0.99)$ were the most important variables in the cat model, whereas sex played a minor role $(\omega=0.24$, Table 4$)$. Based on the averaged model estimates (Fig. 5B), there is evidence that rural cats that received more leftovers brought more prey home than village cats, whereas the cat's sex was a poor predictor. From the collinear variables 
357

358

359

360

361

362

363

364

365

366

367

368

369

370

371

372

373

374

375

376

377

378

379

380

381

382

383

384

385

386

387

removed before modelling, only SIZE had a significant association with LOCATION and PREY, respectively (Fisher's exact tests, $\mathrm{p}<0.001$ ), indicating that not only rural, but also larger dogs were more prone to prey upon wildlife.

[Please insert Table 4 here]

[Please insert Figure 5 here]

Importantly, participants suggested several measures to diminish the number of street dogs, including reproductive control ( $18.9 \%, \mathrm{n}=534$ suggestions), registration (14.6\%), responsible pet husbandry (11.2\%), establishing an animal shelter (10.5\%), education and adoption campaigns $(9.2 \%)$, controls and penalties $(8.4 \%)$, movement restriction $(8.1 \%)$, animal health $(7.3 \%)$, limiting the number of dogs per family or not abandoning dogs (7.1\%), and euthanasia (4.7\%).

\section{Discussion}

In the absence of biological studies, this survey provides a first understanding of the interactions of domestic carnivores with wildlife in a sub-Antarctic wilderness setting. A representative sample of the local population in the Cape Horn Biosphere Reserve gave insight into pet husbandry and perceptions of impacts of free-roaming dogs and cats. We found that freeroaming dog packs were frequently observed (64\% of participants) in natural areas on Navarino Island. Many of these individuals may be owned, as many participants indicated their dogs were not confined (65 of 168 dogs roamed freely day or night, and 22 dogs had even disappeared for $24 \mathrm{~h}$ or more). Further, travel distances of free-roaming owned rural dogs vary, with reports of 4 km (Sepúlveda et al., 2015) or up to 8-30 km (Meek, 1999). However, such large foray distances are an exception. Finding a village dog at a distance $>1 \mathrm{~km}$ from its home had a $10 \%$ chance in a study of dogs scavenging sea-turtle nests (Ruiz-Izaguirre et al., 2014), and most rural dogs even spent $95 \%$ of their time $<200 \mathrm{~m}$ from their households (Sepúlveda et al., 2015).

Our findings indicate that there is evidence of a feral dog population on Navarino Island. The participants reported sightings of unaccompanied dog packs in remote parts of the island (up to $19.4 \mathrm{~km}$ from the northern settled coast, Fig. 2) and sightings of dog pups (feral or abandoned) outside town (52 participants). They identified 52\% of the 172 sightings as feral dogs. This may 
388 be an over-estimate, but given that free-roaming village dogs are easily recognized in the small 389 town of Puerto Williams, it is likely that participants could distinguish between owned and feral 390 dogs. However, it is not clear whether this presumably feral population has achieved long-term 391 human independence, as for example the dogs eradicated from Isabela Island, Galápagos (Reponen 392 et al., 2014). The reported population of abandoned dog pups and missing dogs may have been 393 recruited into feral dog packs (e.g., Boitani et al., 2017). The importance of the local landfill (12 394 sightings of dog packs of 8-11 animals on average) as a food subsidy warrants further investigation, 395 as these novel ecosystems can produce a variety of positive and negative impacts on vertebrate 396 species exploiting them (Boitani et al., 2017; Plaza \& Lambertucci, 2017). For cats, the few 397 sightings ( $5 \%$ of participants) in natural areas were along the northern-settled coast, except for one 398 cat sighted $5.2 \mathrm{~km}$ south of the coast. Further phenotypical, genetic, and ecological research is 399 400 401 needed to better understand the feral dog and possible feral cat population and their impacts on Navarino Island.

Although there were 227 dog sightings during 2014/2015, dog-wildlife conflicts of free402 roaming dogs were hardly recognized (4.5\% of 44 observed problems, Fig. 3). The direct 403 observation of dog-wildlife interactions is probably a rare situation, particularly with mammals, as the mammalian community on Navarino Island is limited (Anderson et al., 2006). Only five 405 terrestrial native species exist: two species each of bats and mice, and the vulnerable guanaco. Among exotic mammals, there are three elusive wild species (North American beaver, American mink Neovison vison, and muskrat) and free-ranging domestic mammals such as cows, horses, sheep, and pigs. Dog interactions with exotic mammals may not have been considered as true wildlife-conflict by the participants as there was a general consensus in the community about the need for a population reduction of exotic mammals such as mink and beavers (Schüttler et al., 411 2011).

Guanacos have not been sighted along the northern coast for many years (González, Zapata \& Marín, 2002), and their densities were as low as 0.14 individuals $/ \mathrm{km}^{2}$ on the northeastern coast of Navarino Island during 2002-2005 (González, 2005). Thus, it is almost impossible to see depredation or harassment of guanacos by dogs (one piece of photographic evidence was taken by Denis Chevallay in 2002). However, individual dog attacks on rare species may impact their persistence substantially (e.g., pudus, Silva-Rodríguez \& Sieving, 2012; mountain gazelles 
418 Gazella gazella, Manor \& Saltz, 2004). Therefore, future studies on dog impacts on the 419 southernmost isolated population of guanacos are an urgent need.

420 The likelihood of interactions among dogs and avian species has the potential to be much

421 higher, as birds, among them many seabirds, are the most diverse and abundant group among 422 vertebrates in the CHBR (Rozzi et al., 2006). Indeed, eleven dogs brought bird prey home, and 30 423 dogs were observed by their owners to harass birds (songbirds, waterbirds, and raptors, Fig. 4). 424 However, these experiences were not translated into the context of a possible "dog-wildlife" 425 conflict: only 9\% of 202 suspected dog problems outside town were dog-wildlife problems (Fig. 426 3); most were dog-domestic animal (54\%) or dog-people conflicts (35\%). On the one hand, this 427 may be due to a lack of knowledge of the local fauna by short-term residents; further, Cape Horn 428 biocultural identity is missing in the classrooms. Rozzi et al. (2008) reported an absence of native 429 fauna in the minds of local short-term residents who primarily mentioned cosmopolitan roses and 430 apple trees as local plant species. On the other hand, the absence of dog-wildlife interactions in the 431 participants' minds might indicate that dogs are mainly perceived as domestic animals that act in 432 a human-dominated context and not as carnivores in a natural ecosystem. Personal safety was also 433 the most common public concern regarding free-roaming dogs and cats in central Italy (Slater et 434 al., 2008). This perception may be attributed to the historical attachment bonding between the dog435 human dyad believed to be similar to a child-parent relationship (review in Payne, Bennett \& 436 McGreevy, 2015).

437 For cats, awareness of possible cat-wildlife problems, particularly with birds, was higher $438(68 \%$ of 77 problems, Fig. 3). On the one hand, these problems might be more visible, at least for 439 cat owners, whose cats brought birds home (37\% of cats in this study, Fig. 4). This number, 440 however, probably clearly underestimates true capture rates, as Loyd et al. (2013) demonstrated 441 with animal-borne video cameras worn by urban cats in the United States (see also Kays \& DeWan, 442 2004). On the other hand, Arahori et al. (2017) showed that owners' views of their cats and dogs 443 differed; for example, cat owners had a weaker tendency to regard their pets as family members 444 than dog owners. This perception may also influence their view on how cats behave outside their 445 homes (i.e., as carnivorous species).

446 Besides prey brought home by dogs and cats, our diet analysis of dog feces showed that 447 dogs indeed preyed upon domestic animals such as cows and horses (64\%); but beavers (14\%) and 448 birds $(10 \%)$ were present in feces as well. This finding is consistent with cow losses reported by 
449 Navarino's farm owners. However, part of the diet might also be a result of scavenging animals 450 that died from other causes, such as disease (e.g., Butler \& du Toit, 2002). More biological 451 methods, such as analyzing cat diet or observations of what free-roaming dogs and cats actually 452 do, are needed to further validate and complement the self-reported observations on wildlife453 interactions in this survey.

454 Finally, with GLMs, we showed that rural provenance, large dog size, and an adequately 455 food supply for cats played a significant role as predictors for bringing wildlife prey home. When 456 rural households are imbedded in wilderness settings and spatial and behavioral barriers between 457 domestic and wild animals lacking, the apparent consequence are higher depredation rates of 458 (larger) dogs and cats on wildlife. Increasing the confinement of those pets should thus be part of 459 management strategies. Unlike other studies, an inadequate food supply (i.e., higher percentage of 460 leftovers) was not associated with dogs preying upon wildlife. This may be due to methodological 461 differences. Silva-Rodríguez \& Sieving (2011) and Ruiz-Izaguirre et al. (2014) considered body 462 condition score and metabolic energy intake, whereas we only relied on the participants' 463 statements. To some extent, the social desirability bias (where the participants wish to appear 464 socially or morally worthy, Maccoby \& Maccoby, 1954) might underlie these differences by biasing results toward more frequent feeding with a commercial food diet. While restricting boundaries for farm dogs and cats is probably a difficult task due to their roles as working dogs or for rodent control, the necessity of improving nutrition could be more acceptable to owners, not only for lowering wildlife depredation, but also for pet welfare. In general, where pet owners are less susceptible to arguments based on wildlife protection, welfare-based arguments (such as reducing risks of road accidents by confinement) could represent an alternative approach to enhance pet husbandry (Hall et al., 2006).

472

\section{Conclusions}

Unconfined dogs and cats in the Cape Horn Biosphere Reserve interact with wildlife, although this is almost unrecognized by the local community, particularly with dogs. To guarantee the future intactness of this wilderness area, it is essential to put the possible impacts of freeroaming pet carnivores on wildlife into perspective. This should be done using an integrative approach that respects the many dimensions of pet carnivores in their beneficial and problematic interactions with their human, conspecific, and natural environment: (1) Although over half of pets 
480 in Puerto Williams were sterilized, encouraging neutering, particularly in rural areas, could reduce 481 pet density and avoid elimination or abandonment of unwanted pups/kittens. Moreover, sterilized 482 dogs were described to show lower rates of escaping from home and less roaming behavior 483 (Neilson, Eckstein \& Hart, 1997; Spain, Scarlett \& Houpt, 2004, but see Garde et al., 2015), which 484 might lower their access to wildlife. (2) Despite its probable unpopularity (e.g., Grayson, Calver 485 \& Styles, 2002), we recommend that dog and cat ownership should be completely banned in 486 families living in Navy posts, as they are located within wild insular environments (some in 487 National Parks) where pet interactions with wildlife can be particularly severe (Medina et al., 2011) 488 and pets can become feral. (3) The evidence of a feral population of dogs on Navarino Island 489 (where native predators are absent) urgently needs biological methods of confirmation such as 490 GPS monitoring (Young et al., 2011) and an assessment of its impacts. Feral dogs are still poorly 491 investigated (Boitani et al., 2017), and management implications for feral dogs are challenging 492 (i.e., they may include the removal of dogs) due to their avoidance of human contact (Boitani \& 493 Ciucci, 1995) and restriction to natural habitats. (4) Increasing dog and cat confinement is 494 beneficial to prevent not only pet-wildlife interactions, but also many socio-economic problems. In-house/yard confinement largely depends upon cultural settings (Hsu, Severinghaus \& Serpell, 496 2003; Jackman \& Rowan, 2007) and is low in many countries in Africa, Asia, and South America 497 (Reece, 2005), including Chile, which has high percentages of free-roaming dogs in rural settings 498 (67\%, Acosta-Jamett et al., 2010; 84-91\% Silva-Rodríguez \& Sieving, 2012; 92\% Sepúlveda et al., 2014). A new Chilean law promoting responsible pet ownership was recently enacted (Ley $21.020,2017$ ) and could be a first step towards regulating confinement by national legislation which was considered far from sufficient in 2014 by Bonacic \& Abarca (2014). Meanwhile, bells, electronic alarms, or colorful collar covers are an option for free-roaming cats to reduce depredation rates on wildlife (Gordon, Matthaei \& Van Heezik, 2010; Calver \& Thomas, 2011; Willson, Okunlola \& Navak, 2015), as well as advice on environmental enrichment techniques for indoor cats (Rochlitz, 2005), outdoor enclosures, and leash training (Hall et al., 2016). (5) Finally, an instrument such as this survey can reveal what problems with free-roaming pets exist; thus, it provides insight into impacts in the absence of biological studies or complementary to them (e.g., dogs interacting with rare and endemic mammals were only detected through interviews in Silva-

509 Rodríguez \& Sieving, 2011). Owners' and non-owners' suggestions can also contribute to creating 510 acceptable measures towards responsible pet ownership (Calver et al., 2011). For the CHBR, in 
511 addition to the above mentioned technical and legal solutions, social change to improve pet

512 management for wildlife benefits could be stimulated through education about the vulnerability of

513 native fauna to dogs and cats, attractive education material such as puppet videos, documentaries,

514 or animal-borne films for school pupils, and action days such as walking with leashed dogs or

515 breakfasts with dog owners (further examples in Miller, Ritchie \& Weston, 2014).

516

\section{Acknowledgements}

518 This work was only possible due to the willingness and interest of the local community of 519 Puerto Williams, farm owners, and Chilean Navy families to participate in our survey. We are 520 grateful to the Chilean Navy for facilitating maritime transport to the Navy posts on different 521 islands within the CHBR. We would like to thank Eduardo Silva for his advice in the questionnaire 522 design and Mariela Alarcon and her team from the Scientific Ethical Committee of the University 523 of Magallanes for improving an earlier version of the questionnaire. Amy Wynia, Nancyrose 524 Houston, and two anonymous reviewers made valuable comments on an earlier version of the 525 manuscript. We are also grateful to Andrés Mansilla and Ricardo Rozzi for their support in this 526 study.

527

528

529

\section{References}

Acosta-Jamett G. 2009. The role of domestic dogs in diseases of significance to humans and wildlife health in central Chile. D. Phil. Thesis, University of Edinburgh.

Acosta-Jamett G, Cleaveland S, Cunningham AA, Bronsvoort BM deC. 2010. Demography of domestic dogs in rural and urban areas of the Coquimbo region of Chile and implications for disease transmission. Preventive Veterinary Medicine 94:272-281.

Anderson CB, Rozzi R, Torres-Mura JC, McGehee SM, Sherriffs MF, Schüttler E, Rosemond AD. 2006. Exotic vertebrate fauna in the remote and pristine sub-Antarctic Cape Horn Archipelago, Chile. Biodiversity and Conservation 15:3295-3313.

Arahori M, Kuroshimaa H, Horia Y, Takagia S, Chijiiwa H, Fujita K. 2017. Owners' view of their pets' emotions, intellect, and mutual relationship: Cats and dogs compared. Behavioural Processes. http://dx.doi.org/10.1016/j.beproc.2017.02.007.

Baker PJ, Boitani L, Harris S, Saunders G, White PCL. 2008. Terrestrial carnivores and human food production: Impact and management. Mammal Review 38:123-166. 
542 Bernard HR. 2006. Research methods in Anthropology. Qualitative and quantitative approaches.

543 Oxford: Altamira Press.

544 Boitani L, Ciucci P. 1995. Comparative social ecology of feral dogs and wolves. Ethology Ecology $545 \quad \&$ Evolution 7: 49-72.

546 Boitani L, Francisci F, Ciucci P, Andreoli G. 2017. The ecology and behavior of feral dogs: A case 547 study from central Italy. In: Serpell J, ed. The domestic dog. Its evolution, behavior and 548 interactions with people. Cambridge: Cambridge University Press, 342-368.

549 Bonacic C, Abarca K. 2014. Hacia una política y legislación para el control de poblaciones de 550 cánidos y calidad de vida de las personas: un enfoque multidisciplinario hacia una política y 551 legislación para el control de poblaciones de cánidos y calidad de vida de las personas. Centro 552 de Políticas Públicas UC 65:1-13.

553 Burnham KP, Anderson DR. 2002. Model selection and multimodel inference. A practical 554 information-theoretic approach. New York: Springer.

555 Butler JRA, du Toit JT. 2002. Diet of free-ranging domestic dogs (Canis familiaris) in rural 556 Zimbabwe: implications for wild scavengers on the periphery of wildlife reserves. Animal 557 Conservation 5:29-37.

558 Butler JRA, du Toit JT, Bingham J. 2004. Free-ranging domestic dogs Canis familiaris as 559 predators and prey in rural Zimbabwe: threats of competition and disease to large wild 560 carnivores. Biological Conservation 115:369-378.

561 Calver MC, Grayson J, Lilith M, Dickman CR. 2011. Applying the precautionary principle to the 562 issue of impacts by pet cats on urban wildlife. Biological Conservation 144:1895-1901.

563 Calver MC, Thomas S. 2011. Effectiveness of the Liberator ${ }^{\mathrm{TM}}$ in reducing predation on wildlife 564 by domestic cats. Pacific Conservation Biology 16:244-250.

565 Chehébar C, Martín S. 1989. Guía para el reconocimiento microscópico de los pelos de los 566 mamíferos de la Patagonia. Doñana Acta Vertebrata 16:247-291.

567 Cunazza C. 1991. El guanaco, una especie de fauna silvestre con futuro. Corporación Nacional 568 Forestal, Report Gerencia Técnica, Santiago, Chile.

569 Doherty TS, Dickman CR, Glen AS, Newsome TM, Nimmo DG, Ritchie EG, Vanak AT, Wirsing 570 AJ. 2017. The global impacts of domestic dogs on threatened vertebrates. Biological 571 Conservation 210:56-59. 
572 Echegaray J, Vilà C. 2010. Noninvasive monitoring of wolves at the edge of their distribution and 573 the cost of their conservation. Animal Conservation 13:157-161.

574 Garde E, Pérez PE, Vanderstichel R, Dalla Villa PF, Serpell JA. 2015. Effects of surgical and 575 chemical sterilization on the behavior of free-roaming male dogs in Puerto Natales, Chile. 576 Preventive Veterinary Medicine 123:106-120.

577 Gompper ME. 2014a. The dog-human-wildlife interface: assessing the scope of the problem. In: 578 Gompper ME, ed. Free-ranging dogs and Wildlife Conservation. Oxford: Oxford University 579 Press, 9-54.

580 Gompper ME. 2014b. Introduction: outlining the ecological influences of a subsidized 581 domesticated predator. In: Gompper ME, ed. Free-ranging dogs and Wildlife Conservation. 582 Oxford: Oxford University Press, 1-8.

583 González-Esteban J, Villate I, Irizar I. 1996. Differentiating hair samples of the European mink 584 (Mustela lutreola), the American mink (Mustela vison) and the European polecat (Mustela 585 putorius) using light microscopy. Journal of Mammalogy 270:458-461.

586 González BA. 2005. Informe sobre la situación de conservación de la población de guanacos 587 (Lama guanicoe) en la costa Noroeste de isla Navarino, XII Región de Chile. Report, Fundación 588 Biodiversitas, Chile.

589 González B, Zapata B, Marín JC. 2002. Situación de conservación y percepción local sobre la 590 población de guanacos más austral del mundo, Isla Navarino, XII Región de Chile. Report, 591 Pontificia Universidad Católica de Chile.

592 Gordon JK, Matthaei C, Van Heezik Y. 2010. Belled collars reduce catch of domestic cats in New 593 Zealand by half. Wildlife Research 37:372-378.

594 Gramza A, Teel T, VandeWoude S, Crooks K. 2016. Understanding public perceptions of risk 595 regarding outdoor pet cats to inform conservation action. Conservation Biology 30:276-286.

596 Grayson J, Calver MC, Styles I. 2002. Attitudes of suburban Western Australians to proposed cat 597 control legislation. Australian Veterinary Journal 80:536-543.

598 Hall CM, Adams NA, Bradley JS, Bryant KA, Davis AA, Dickman CR, Fjuita T, Kobayashi S, 599 Lepczyk CA, McBride EA, Pollock KH, Styles IM, van Heezik Y, Wang F, Calver MC. 2016. 600 Community attitudes and practices of urban residents regarding predation by pet cats on 601 wildlife: an international comparison. PLoS ONE 11(4): e0151962. 
602 Hart LA, Yamamoto M. 2017. Dogs as helping partners and companions for humans. In: Serpell $603 \mathrm{~J}$, ed. The domestic dog. Its evolution, behavior and interactions with people. Cambridge: 604 Cambridge University Press, 247-270.

605 Hsu Y, Severinghaus LL, Serpell JA. 2003. Dog keeping in Taiwan: its contribution to the problem 606 of free-roaming dogs. Journal of Applied Animal Welfare Science 6:1-23.

607 Hughes J, Macdonald DW. 2013. A review of the interactions between free-roaming domestic 608 dogs and wildlife. Biological Conservation 157:341-351.

609 Hughes KA, Pertierra LR, Molina-Montenegro MA, Convey P. 2015. Biological invasions in 610 terrestrial Antarctica: what is the current status and can we respond? Biodiversity and 611 Conservation 24:1031-1055.

612 Jackman J, Rowan A. 2007. Free-roaming dogs in developing countries: The benefits of capture, 613 neuter, and return programs. In: Salem DJ, Rowan AN, eds. The state of the animals. 614 Washington, DC: Humane Society Press, 55-78.

615 Kays RW, DeWan AA. 2004. Ecological impact of inside/outside house cats around a suburban 616 nature preserve. Animal Conservation 7:273-283.

617 Ley 21.020. 2017. Sobre tenencia responsable de mascotas y animales de compañía. Available at 618 https://www.leychile.cl/Navegar?idNorma=1106037\&r=6 (accessed 15 September 2017).

619 Loyd KAT, Hernandez SM, Carroll JP, Abernathy KJ, Marshall GJ. 2013. Quantifying free620 roaming domestic cat predation using animal-borne video cameras. Biological Conservation $621 \quad 160: 183-189$.

622 Maccoby EE, Maccoby N. 1954. The interview: A tool of social science. In: Lindzey G, ed. 623 Handbook of Social Psychology. Cambridge: Addison-Wesley, 449-487.

624 Manor R, Saltz D. 2004. The impact of free-roaming dogs on gazelle kid/female ratio in a 625 fragmented area. Biological Conservation 119:231-236.

626 Matter HC, Daniels TJ. 2000. Dog ecology and population biology. In: Macpherson CNL, Meslin, 627 F, Wandeler AI, eds. Dogs, zoonoses and public health. Wallingford: CABI Publishing, 17-50. 628 Medina FM, Bonnaud E, Vidal E, Tershy BR, Zavaleta ES, Donlan CJ, Keitt BS, Le Corre M, 629 Horwath SV, Nogales M. 2011. A global review of the impacts of invasive cats on island 630 endangered vertebrates. Global Change Biology 17:3503-3510.

631 Meek PD. 1999. The movement, roaming behavior and home range of free-roaming domestic 632 dogs, Canis lupus familiaris, in coastal New South Wales. Wildlife Research 26:847-855. 
633 Miller KK, Ritchie EG, Weston MA. 2014. The human dimensions of dog-wildlife interactions. 634 In: Gompper ME, ed. Free-ranging dogs and Wildlife Conservation. Oxford: Oxford University 635 Press, 286-304.

636 Mitchell BD, Banks PB. 2005. Do wild dogs exclude foxes? Evidence for competition from dietary 637 and spatial overlap. Australian Ecology 30:581-591.

638 Mittermeier RA, Mittermeier CG, Brooks TM, Pilgrim JD, Konstant WR, da Fonseca GAB, 639 Kormos C. 2003. Wilderness and biodiversity conservation. Proceedings of the National 640 Academy of Sciences of the United States of America 18:10309-10313.

641 Mundry R. 2014. Statistical issues and assumptions of phylogenetic generalized least squares. In: 642 Garamszegi L, ed. Modern phylogenetic comparative methods and their application in 643 Evolutionary Biology. Berlin, Heidelberg: Springer, 131-153.

644 Neilson JC, Eckstein RA, Hart BL. 1997. Effects of castration on problem behaviors in male dogs 645 with reference to age and duration of behavior. Journal of the American Veterinary Medical 646 Association 211:180-182.

647 Nogales M, Vidal E, Medina FM, Bonnaud E, Tershy BR, Campbell KJ, Zavaleta ES. 2013. Feral 648 cats and biodiversity conservation. The urgent prioritization of island management. BioScience $649 \quad 63: 804-810$.

650 O’Brien SJ, Johnson WE. 2007. The evolution of cats. Scientific American 297:68-75.

651 Payne E, Bennett PC, McGreevy PD. 2015. Current perspectives on attachment and bonding in 652 the dog-human dyad. Psychology Research and Behaviour Management 8:71-79.

653 Pisano E. 1977. Fitogeografía de Fuego-Patagonia chilena. I. Comunidades vegetales entre las 654 latitudes 52 y 56 S. Anales del Instituto de la Patagonia 8:121-250.

655 Plaza PI, Lambertucci SA. 2017. How are garbage dumps impacting vertebrate demography, 656 health, and conservation? Global Ecology and Conservation 12:9-20.Randi E. 2008. Detecting 657 hybridization between wild species and their domesticated relatives. Molecular Ecology $658 \quad 17: 285-293$.

659 R Core Team. 2016. R: A language and environment for statistical computing. R Foundation for 660 Statistical Computing, Vienna, Austria. Available at https://www.R-project.org/.

661 Reece JF. 2005. Dogs and dog control in developing countries. In: Salem DJ, Rowan AN, eds. The 662 state of the animals III, Washington, D.C.: Humane Society Press, 55-64. 
663 Reponen SEM, Brown SK, Barnett BD, Sacks BN. 2014. Genetic and morphometric evidence on 664 a Galápagos Island exposes founder effects and diversification in the first-known (truly) feral 665 western dog population. Molecular Ecology 23:269-283.

666 Rochlitz I. 2005. A review of the housing requirements of domestic cats (Felis silvestris catus) 667 kept in the home. Applied Animal Behaviour Science 93:97-109.

668 Rozzi R, Massardo F, Berghöfer A, Anderson CB, Mansilla A, Mansilla M, Plana J, Berghöfer U, 669 Araya P, Barros E. 2006. Cape Horn Biosphere Reserve: Nomination document for the 670 incorporation of the Cape Horn Archipelago Territory into the Word Biosphere Reserve 671 Network. MaB Program - UNESCO. Punta Arenas: Ediciones de la Universidad de 672 Magallanes.

673 Rozzi R, Arango X, Massardo F, Anderson C, Heidinger K, Moses K. 2008. Field environmental 674 philosophy and biocultural conservation: The Omora Ethnobotanical Park Educational 675 Program. Environmental Ethics 30:325-336.

676 Ruiz-Izaguirre E, van Woersem A, Eilers K, van Wieren SE, Bosch G, van der Zijpp AJ, de Boer 677 IJM. 2014. Roaming characteristics and feeding practices of village dogs scavenging sea-turtle 678 nests. Animal Conservation 18:146-156.

679 Schalamon J, Ainoedhofer H, Singer G, Petnehazy T, Mayr J, Kiss K, Höllwarth ME. 2006. 680 Analysis of dog bites in children who are younger than 17 years. Pediatrics 117:e374-e379.

681 Schüttler E, Klenke R, McGehee S, Rozzi R, Jax K. 2009. Vulnerability of ground-nesting 682 waterbirds to predation by invasive American mink in the Cape Horn Biosphere Reserve, Chile. 683 Biological Conservation 142:1450-1460.

684 Schüttler E, Rozzi R, Jax K. 2011. Towards a societal discourse on invasive species management: 685 A case study of public perceptions of mink and beavers in Cape Horn. Journal for Nature 686 Conservation 19:175-184.

687 Sepúlveda MA, Singer RS, Silva-Rodríguez E, Stowhas P, Pelican K. 2014. Domestic dogs in 688 rural communities around protected areas: conservation problem or conflict solution? PLoS 689 ONE 9(1): e86152.

690 Sepúlveda MA, Pelican K, Cross P, Egurenc A, Singer R. 2015. Fine-scale movements of rural 691 free-ranging dogs in conservation areas in the temperate rainforest of the coastal range of 692 southern Chile. Mammalian Biology 80:290-297. 
693 Sih A, Bolnick DI, Luttbeg B, Orrock JL, Peacor SD, Pintor LM, Preisser E, Rehage JS, Vonesh 694 JR. 2010. Predator-prey naïveté, antipredator behavior, and the ecology of predator invasions. 695 Oikos 119:610-621.

696 Silva-Rodríguez EA, Ortega-Solís GR, Jiménez JE. 2010. Conservation and ecological 697 implications of the use of space by chilla foxes and free-ranging dogs in a human-dominated 698 landscape in southern Chile. Austral Ecology 35:765-777.

699 Silva-Rodriguez EA, Sieving KE. 2011. Influence of care of domestic carnivores on their predation 700 on vertebrates. Conservation Biology 25:808-815.

701 Silva-Rodriguez EA, Sieving KE. 2012. Domestic dogs shape the landscape-scale distribution of 702 a threatened forest ungulate. Biological Conservation 150:103-110.

703 Slater MR, Di Nardo A, Pediconi O, Villa PD, Candeloro L, Alessandrini B, Del Papa S. 2008. 704 Free-roaming dogs and cats in central Italy: public perceptions of the problem. Preventive $705 \quad$ Veterinary Medicine 84:27-47.

706 Spain CV, Scarlett JM, Houpt KA. 2004. Long-term risks and benefits of early-age gonadectomy 707 in dogs. Journal of the American Veterinary Medical Association 224:380-387.

708 Symonds MRE, Moussalli A. 2011. A brief guide to model selection, multimodel inference and 709 model averaging in behavioural ecology using Akaike's Information Criterion. Behavioral 710 Ecology and Sociobiology 65:13-21.

711 Vanak AT, Gompper ME. 2009. Dogs Canis familiaris as carnivores: their role and function in 712 intraguild competition. Mammal Review 39:265-283.

713 Vanak AT, Thaker M, Gompper ME. 2009. Experimental examination of behavioural interactions 714 between free-ranging wild and domestic canids. Behavioral Ecology and Sociobiology 64:279715 287. White PCL, Jennings NV, Renwick AR, Barker NHL. 2005. Questionnaires in ecology: a 716 review of past use and recommendations for best practice. Journal of Applied Ecology 42:421$717 \quad 430$.

718 Williams KJH, Weston MA, Henry S, Maguire GS. 2009. Birds and beaches, dogs and leashes: 719 Dog owners' sense of obligation to leash dogs on beaches in Victoria, Australia. Human 720 Dimensions of Wildlife 14:89-101.

721 Willson SK, Okunlola IA, Novak JA. 2015. Birds be safe: Can a novel cat collar reduce avian 722 mortality by domestic cats (Felis catus)? Global Ecology and Conservation 3:359-366. Woods 
723 M, McDonald RA, Harris S. 2003. Predation of wildlife by domestic cats Felis catus in Great $724 \quad$ Britain. Mammal Review 33:174-188.

725 Young JK, Olson, KA, Reading RP, Amgalanbaatar S, Berger J. 2011. Is wildlife going to the 726 dogs? Impacts of feral and free-roaming dogs on wildlife populations. BioScience 61:125-132. 727 Zuur AF, Ieno EN, Elphick CS. 2010. A protocol of data exploration to avoid common statistical 728 problems. Methods in Ecology \& Evolution 1:3-14. 


\section{Figure 1}

Map of the Cape Horn Biosphere Reserve, southern Chile.

The Alberto de Agostini and Cape Horn National Parks are core areas of the CHBR and Yendegaia (in light grey) is a recently-created national park. The only large settlement $(2,800$ inhabitants) is Puerto Williams, on Navarino Island. Eleven Chilean Navy posts are located throughout the reserve on Tierra del Fuego Island $(n=2)$, Navarino Island $(n=2)$, and uninhabited islands $(n=7)$; all are only accessible via maritime transport, except the western Navy post on Navarino Island.

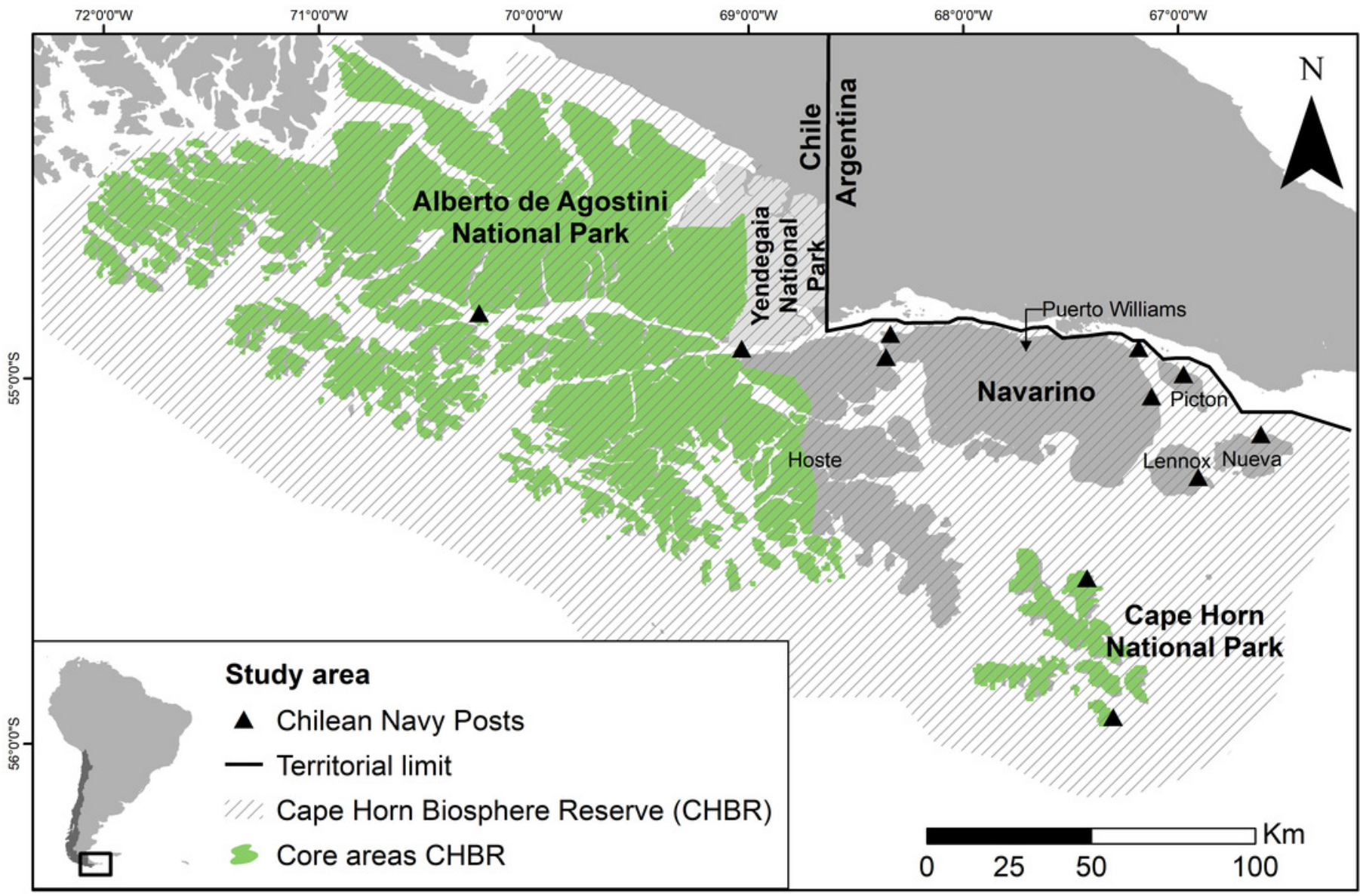




\section{Figure 2}

Free-roaming dog and cat sightings on Navarino Island, southern Chile.

Approximate sighting locations of unaccompanied adult dogs and cats, dog pups (abandoned or feral), and kittens (abandoned) from $n=227$ sightings by 143 participants during 2014/15.

Dog sightings are shown in different classes of pack size.

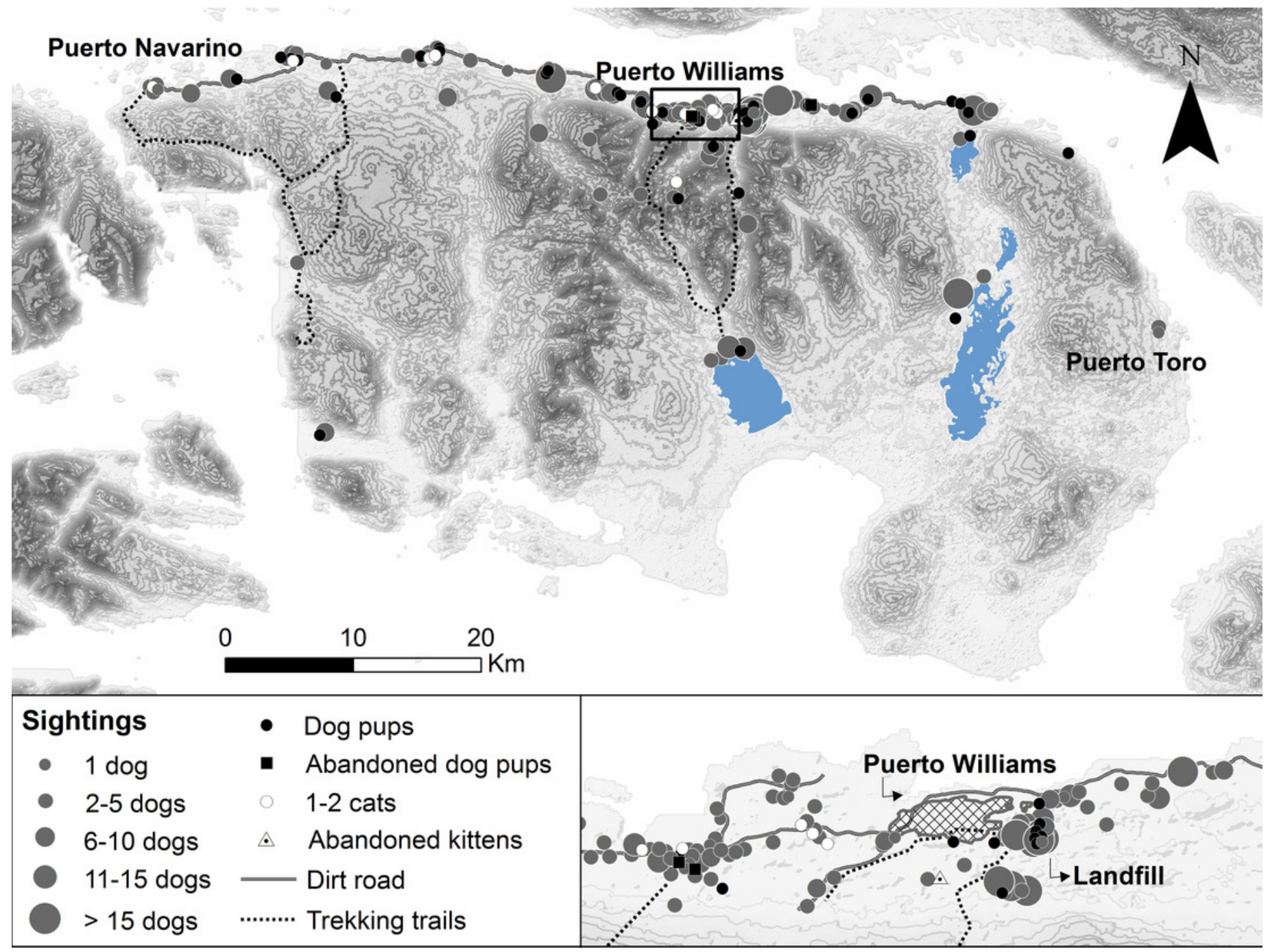




\section{Figure 3}

Experienced and suspected problems with dogs and cats in southern Chile.

Problematic experiences with dogs during 2009-2015 A) inside $(n=143)$ and B) outside $(n=44)$ of Puerto Williams, suspected dog problems (first problem mentioned) C) inside ( $n=221)$ and $D)$ outside of town $(n=202)$, and suspected cat problems (first problem mentioned) E) outside of town ( $n=77)$. Conflicts with people included biting, attacking, frightening, disease transmitting, accidents, and stealing. Dog-domestic animal problems referred to killing, attacking, or feeding on free-ranging domestic animals such as cows, horses (Equus caballus), sheep, pigs (Sus scrofa), and cats, whereas cat-domestic animal problems referred to preying upon chickens (Gallus gallus domesticus). Conflicts with wildlife included killing wild animals such as birds and their eggs, North American beavers (Castor canadensis), and guanacos, or harming ecosystems. Conflicts with conspecifics were fights among dog packs or between cats, and disease transmission. Dog feces and waste dispersing were considered as hygienic problems. "Other" includes dog and cat overpopulation, bad image for tourists, and barking. Images of animals represent predominant animals involved in dog/cat problems. 
Experienced dog problems (\%) Suspected dog problems (\%) Suspected cat problems (\%)

A Inside town

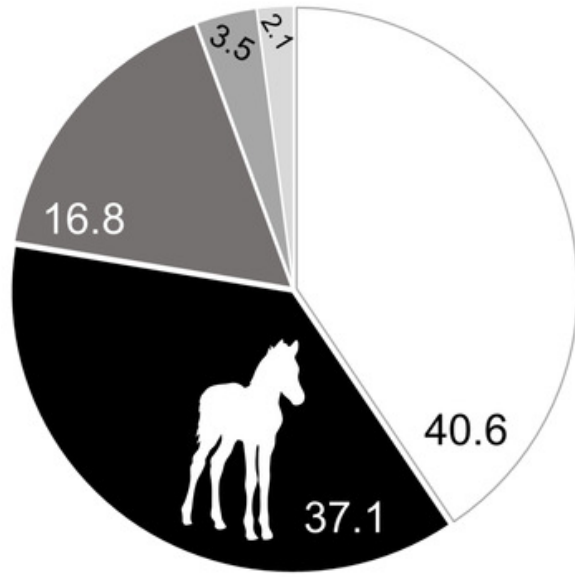

B Outside town

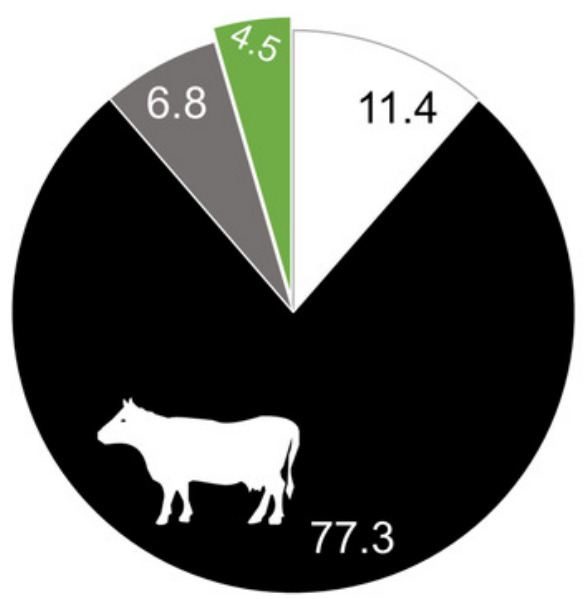

C Inside town

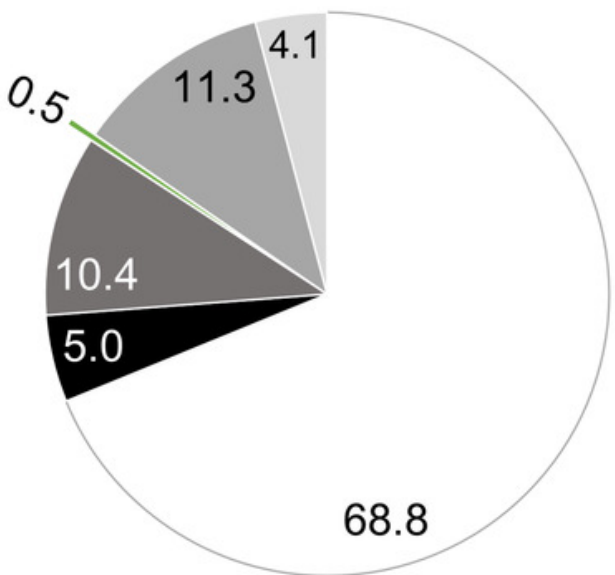

D Outside town

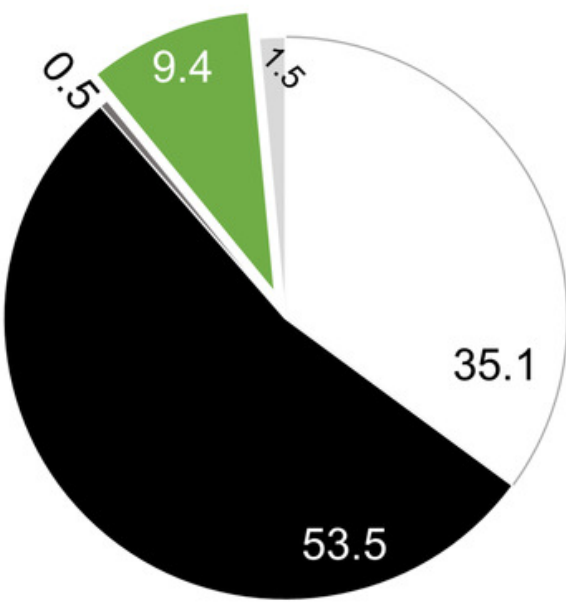

Problems with:

People

Domestic animals

Conspecifics

Wildlife

Hygiene

Other

E Outside town

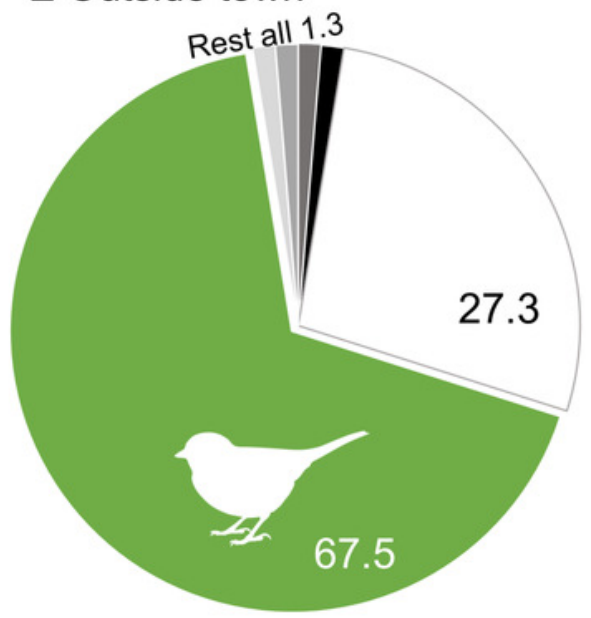




\section{Figure 4}

Preyed and harassed animals by dogs and cats, and suspected feral dog prey in southern Chile.

Prey brought to owners by 31 of 168 dogs ( $n=40$ mentioned items), animals observed to be harassed by 64 dogs ( $n=79$ items), prey brought to owners by 27 of 52 cats ( $n=33$ items), animals observed to be harassed by 19 cats ( $n=25$ items), and suspected prey of feral dogs ( $n=494$ items) by 244 participants. "Other" includes fish (dog prey); fish, foxes, and seals, (harassed by dogs); bats (cat prey); and bird and horse feces, fish bait, foxes, seals, and vegetable material (suspected feral dog prey). "Small livestock" refer to chickens, pigs, and sheep. All bird species mentioned were native, except for the house sparrow, species mentioned among the cat prey. 


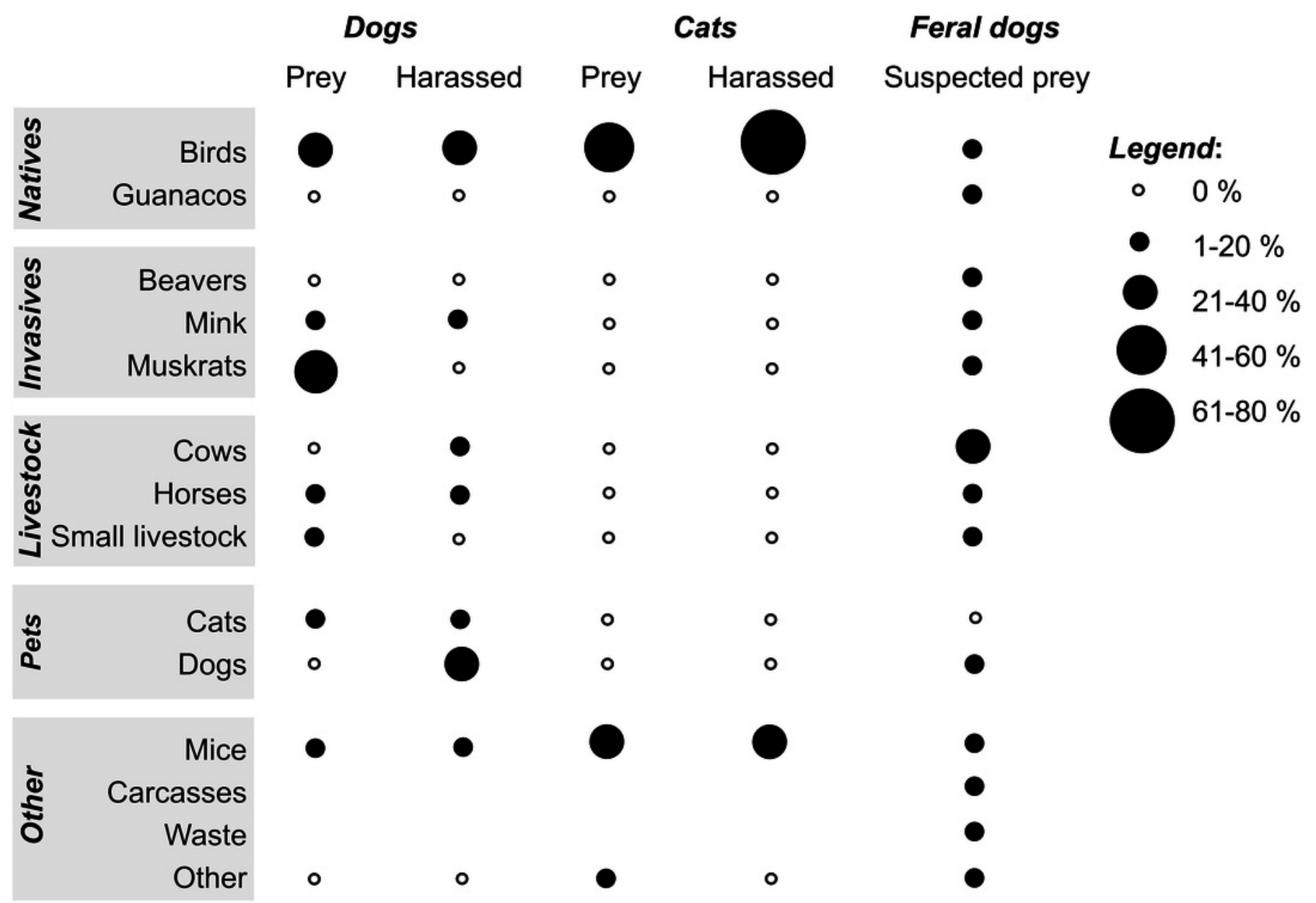




\section{Figure 5}

Model averaged odds ratios for models predicting dog and cat wildlife interactions in southern Chile.

Plots show the model averaged parameter estimates as odds ratios on a log scale with $95 \%$ confidence intervals ( $\mathrm{Cl})$ for $\mathrm{A}$ ) dog model and B) cat model, where LOCATION (dogs and cats) and FOOD (only cats) best predicted whether pets brought wildlife prey home. The other variables had confidence intervals that clearly overlapped the dashed line at 1, which implies that there is no direction of the parameter estimate. 


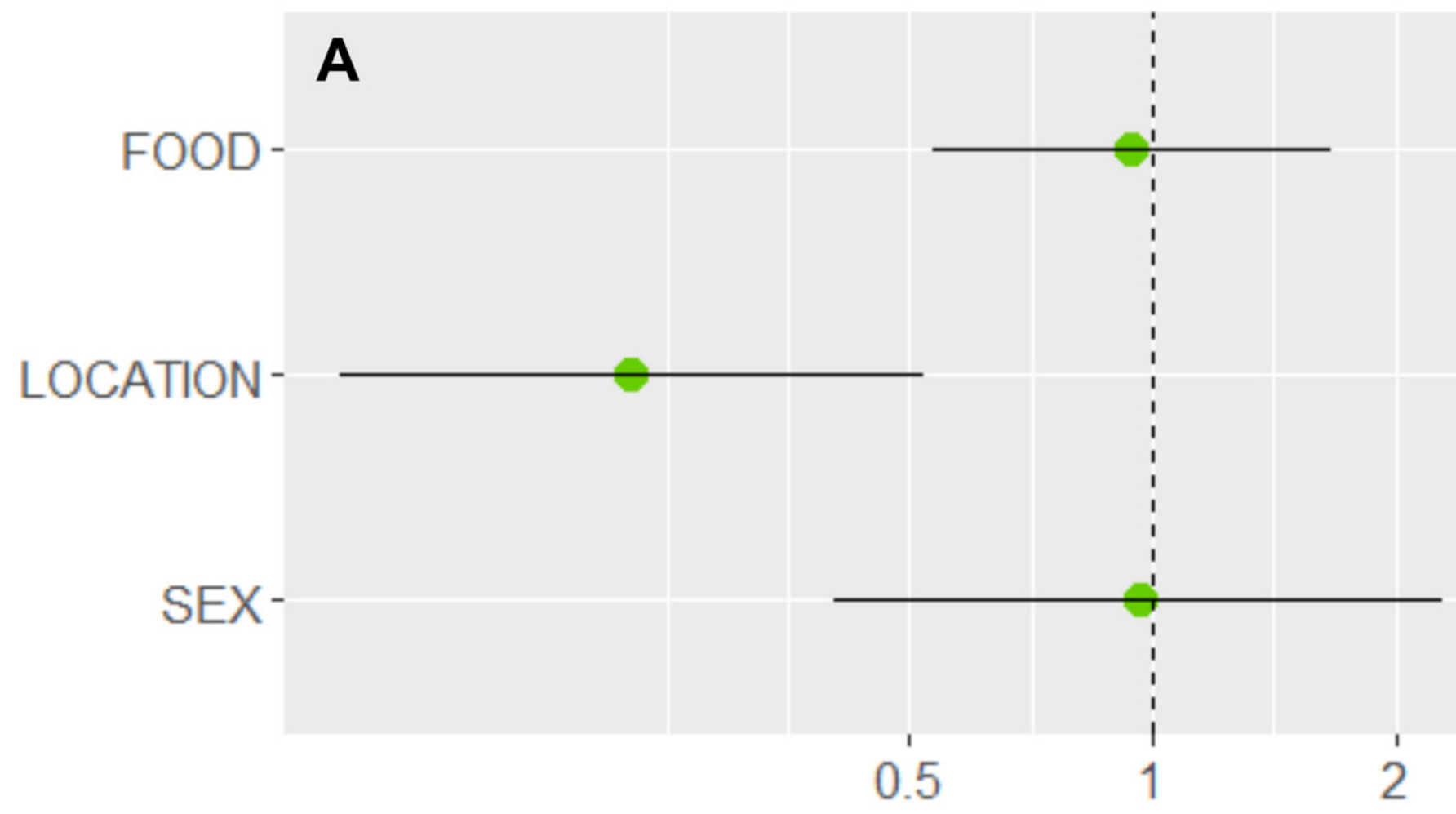

Odds ratio (log scale) and $95 \% \mathrm{Cl}$

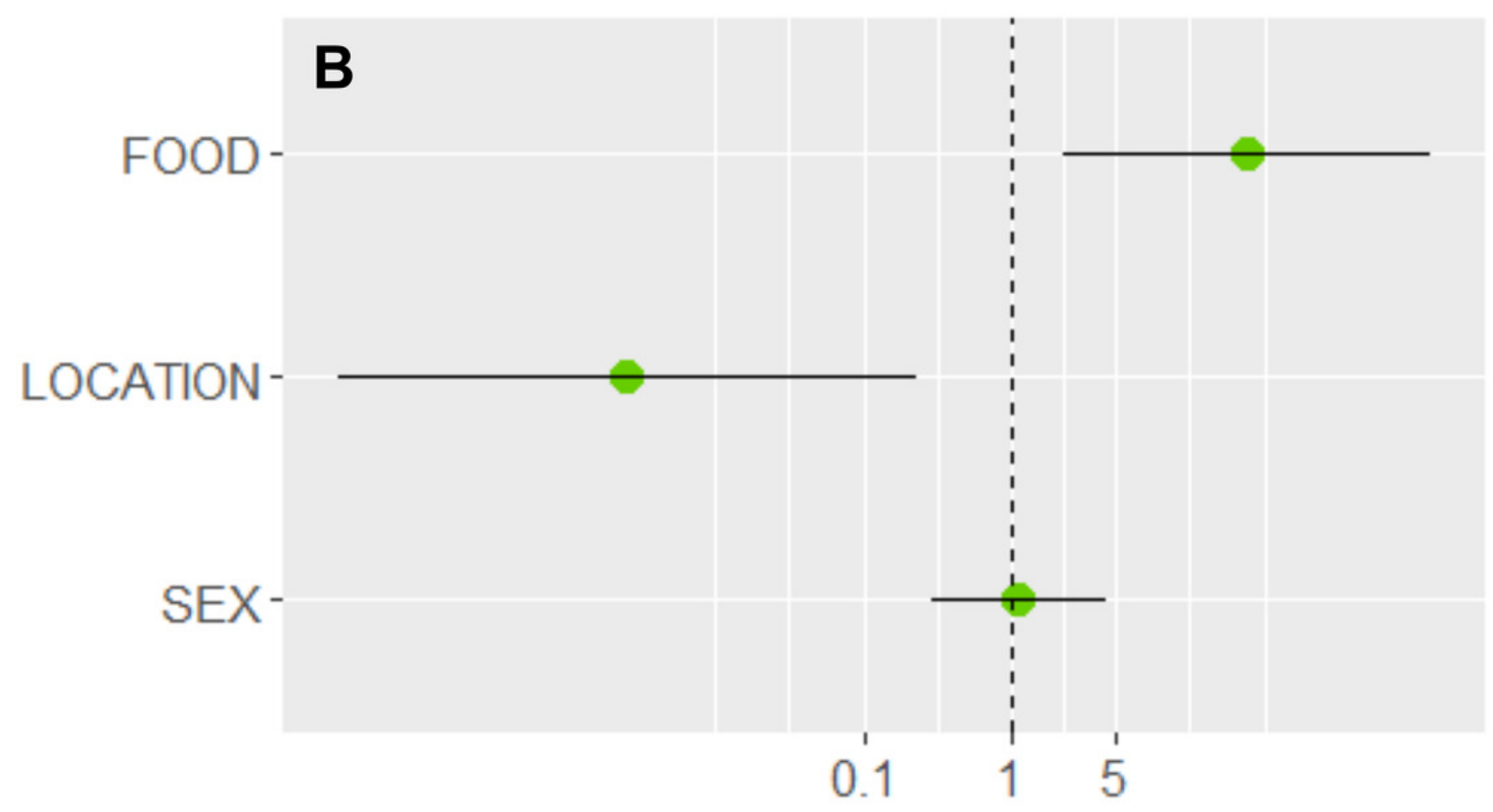

Odds ratio (log scale) and $95 \% \mathrm{Cl}$ 


\section{Table $\mathbf{1}$ (on next page)}

Candidate models for predicting dog and cat wildlife interactions in southern Chile.

A detailed description of the response and predictor variables is provided in Table 2 . 


\begin{tabular}{lllll}
\hline $\begin{array}{l}\text { Candidate } \\
\text { model sets }\end{array}$ & $\begin{array}{l}\text { Response } \\
\text { variable }\end{array}$ & $\begin{array}{l}\text { Quantitative value of } \\
\text { response variable }\end{array}$ & Predictor variables & n** \\
\hline Dog model & PREY & $\begin{array}{l}19.0 \% \text { of dogs brought } \\
\text { prey home }\end{array}$ & FOOD+LOCATION+SEX & 163 \\
& & & $\begin{array}{l}\text { SIZE* } \\
\text { STERILIZED* }\end{array}$ & \\
& & & FOOD+LOCATION+SEX & 52 \\
Cat model & PREY & $\begin{array}{l}51.9 \% \text { of cats brought } \\
\text { prey home }\end{array}$ & STERILIZED* &
\end{tabular}

$1 *$ Predictor variables not included in final model set due to collinearity

$2 * *$ We deleted five missing observations from the dog model (3.0\%) and one from the cat model (1.9\%)

3

4 


\section{Table 2 (on next page)}

Variable description of candidate models for predicting dog and cat wildlife interactions in southern Chile.

The variable description refers to the questionnaire (see Supplementary Material S1). 


\begin{tabular}{|c|c|c|c|}
\hline Variable & $\begin{array}{l}\text { Variable } \\
\text { type }\end{array}$ & $\begin{array}{l}\text { Variable description and } \\
\text { question number }\end{array}$ & Categories \\
\hline PREY & Response & $\begin{array}{l}\text { Dog/cat brought wildlife } \\
\text { prey home (Q25) }\end{array}$ & Yes/no \\
\hline FOOD & Predictor & $\begin{array}{l}\text { Feeding of participant's } \\
\text { dog/cat with leftovers, } \\
\text { commercial food/meat, or } \\
\text { both (Q15) }\end{array}$ & $\begin{array}{l}0=\text { leftovers } \\
1=\text { leftovers and commercial } \\
\text { food } / \text { meat } \\
2=\text { commercial food } / \text { meat }\end{array}$ \\
\hline LOCATION & Predictor & $\begin{array}{l}\text { Dog/cat lives in rural } \\
\text { environment (farm /Navy } \\
\text { post) or in Puerto } \\
\text { Williams }\end{array}$ & Rural/village \\
\hline SEX & Predictor & Dog's/cat's sex (Q2) & $\mathrm{F}=$ Female, $\mathrm{M}=$ Male \\
\hline SIZE* & Predictor & $\begin{array}{l}\text { Dog's size (mean of two } \\
\text { independent estimations } \\
\text { by ES and LSA, Q42) }\end{array}$ & $\begin{array}{l}1=\text { small, } 1.5=\text { small to medium-sized, } \\
2=\text { medium-sized, } 2.5=\text { medium-sized } \\
\text { to large, } 3=\text { large }\end{array}$ \\
\hline STERILIZED & Predictor & $\begin{array}{l}\text { Dog/cat is sterilized } \\
\text { (Q11) }\end{array}$ & $\begin{array}{l}0=\text { not sterilized } \\
1=\text { pet's age }<1 \text { year } \\
2=\text { sterilized }\end{array}$ \\
\hline
\end{tabular}

$1 *$ Variable only used in the dog model, not in the cat model 


\section{Table 3(on next page)}

Demographic dog and cat data, and husbandry results from southern Chile.

We obtained data on owned dog and cat populations via questionnaires from households in Puerto Williams $(n=215)$, accessible farm households on Navarino Island $(n=7)$, and Navy families ( $n=22$, data from two years) living on the 11 Navy posts on different islands within the CHBR. 


\begin{tabular}{|c|c|c|c|c|c|c|}
\hline & \multicolumn{2}{|c|}{$\begin{array}{c}\text { Town households } \\
(\mathrm{n}=215)\end{array}$} & \multicolumn{2}{|c|}{$\begin{array}{c}\text { Farm households } \\
\qquad(\mathrm{n}=7)\end{array}$} & \multicolumn{2}{|c|}{$\begin{array}{c}\text { Navy posts } \\
(\mathrm{n}=22)\end{array}$} \\
\hline & Dogs & Cats & Dogs & Cats & Dogs & Cats \\
\hline \multicolumn{7}{|l|}{ Demographic data } \\
\hline $\begin{array}{l}\text { Households with pet } \\
\text { ownership (\%) }\end{array}$ & $85(39.5)$ & $30(14.0)$ & $6(85.7)$ & $6(85.7)$ & $19(86.4)$ & $4(18.2)$ \\
\hline $\begin{array}{l}\text { Mean pet number per } \\
\text { household (SD) }\end{array}$ & $1.4(0.9)$ & $1.2(0.6)$ & $5(3.3)$ & $2.5(2.5)$ & $1.3(0.5)$ & $1.0(0.0)$ \\
\hline Total pet number & 121 & 36 & 30 & 15 & 17 & 2 \\
\hline Male:female ratio & $1.3: 1$ & $0.7: 1$ & $2: 1$ & $0.3: 1$ & $0.7: 1$ & $0: 1$ \\
\hline Mean pet age (SD) & $3.7(3.8)$ & $4.8(4.1)$ & $3.8(4.6)$ & $3.0(3.0)$ & $3.0(3.7)$ & $3.3(1.1)$ \\
\hline $\begin{array}{l}\text { Number of offspring in } \\
\text { previous year }\end{array}$ & 16 & 0 & 21 & 7 & 9 & 0 \\
\hline Local origin $(\mathrm{CHBR}, \%)$ & 66.1 & 66.7 & 100 & 100 & 29.4 & 100 \\
\hline \multicolumn{7}{|l|}{ Reproductive control } \\
\hline Females spayed; & 66.7 & 71.4 & 10.0 & 8.3; & 11.1; & 0.0 \\
\hline males neutered $(\%)$ & 52.2 & 93.3 & 20.0 & 0.0 & 16.7 & 0.0 \\
\hline \multicolumn{7}{|l|}{ Health } \\
\hline $\begin{array}{l}\text { Vaccinated against } \\
\text { rabies }(\%)\end{array}$ & 55.4 & 33.3 & 0.0 & 0.0 & 64.7 & 0.0 \\
\hline Treated for parasites $(\%)$ & 60.3 & 36.1 & 100.0 & 40.0 & 64.7 & 50.0 \\
\hline \multicolumn{7}{|l|}{ Food provisioning } \\
\hline $\begin{array}{l}\text { Commercial food and/or } \\
\text { meat }(\%)\end{array}$ & 77.7 & 94.4 & 86.7 & 20.0 & 82.3 & 50.0 \\
\hline Leftovers $(\%)$ & 12.4 & 0.0 & 13.3 & 33.3 & 5.9 & 0.0 \\
\hline Mix of above (\%) & 9.9 & 5.6 & 0.0 & 46.7 & 11.8 & 50.0 \\
\hline \multicolumn{7}{|l|}{ Dog confinement } \\
\hline $\begin{array}{l}\text { Free-roaming during } \\
\text { day or night }(\%)\end{array}$ & 30.6 & - & 46.7 & - & 82.4 & - \\
\hline 24-h free-roaming $(\%)$ & 19.0 & - & 30.0 & - & 41.2 & - \\
\hline
\end{tabular}


Table 4(on next page)

Best-ranked generalized linear models for predicting dog and cat wildlife interactions in southern Chile.

Summary of model selection for models with $\triangle \mathrm{AIC}_{\mathrm{c}}<2 . \mathrm{K}$ indicates number of parameters per model, $\Delta \mathrm{AIC}_{\mathrm{c}}$ distance from lowest $\mathrm{AIC}_{\mathrm{c}}$, and $\omega_{\mathrm{i}}$ model weight. 


\begin{tabular}{llllll}
\hline Model set & Competing models & $\boldsymbol{k}$ & $\boldsymbol{A I C}_{\boldsymbol{c}}$ & $\Delta \boldsymbol{A I C _ { \boldsymbol { c } }}$ & $\boldsymbol{\omega}_{\boldsymbol{i}}$ \\
\hline Dog model & FOOD+LOCATION & 3 & 150.72 & 0.00 & 0.37 \\
& LOCATION & 2 & 151.03 & 0.32 & 0.32 \\
& FOOD+LOCATION+SEX & 4 & 152.32 & 1.60 & 0.17 \\
\hline Cat model & FOOD+LOCATION & 3 & 62.19 & 0.00 & 0.75
\end{tabular}

1

2 